Canadian

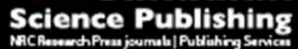

Canadian Journal of Physiology and Pharmacology Revue canadienne de physiologie et pharmacologie

\title{
Protective effect of (-)-a-Bisabolol on rotenone-induced toxicity in Drosophila melanogaster
}

\begin{tabular}{|c|c|}
\hline Journal: & Canadian Journal of Physiology and Pharmacology \\
\hline Manuscript ID & cjpp-2017-0207.R2 \\
\hline Manuscript Type: & Article \\
\hline Date Submitted by the Author: & 06-Jul-2017 \\
\hline Complete List of Authors: & $\begin{array}{l}\text { Leite, Gerlânia; Universidade Federal de Santa Maria } \\
\text { Ecker, Assis; Universidade Federal de Santa Maria } \\
\text { Seeger, Rodrigo; Universidade Federal de Santa Maria } \\
\text { Krum, Bárbara; Universidade Federal de Santa Maria } \\
\text { Lugokenski, Thiago; Universidade Federal dos Pampas } \\
\text { Fachinetto, Roselei; Universidade Federal de Santa Maria } \\
\text { Sudati, Jéssie ; Universidade Federal dos Pampas } \\
\text { Barbosa, Nilda; Universidade Federal de Santa Maria } \\
\text { Wagner, Caroline; Universidade Federal dos Pampas, }\end{array}$ \\
\hline $\begin{array}{r}\text { Is the invited manuscript for } \\
\text { consideration in a Special } \\
\text { Issue?: }\end{array}$ & N/A \\
\hline Keyword: & $\begin{array}{l}<\mathrm{i}>\text { Drosophila melanogaster }</ \mathrm{i}>,(-)-\mathrm{a}-\mathrm{bisabolol} \text {, oxidative stress, } \\
\text { rotenone }\end{array}$ \\
\hline
\end{tabular}

\section{SCHOLARONE \\ Manuscripts}


Protective effect of (-)-a-Bisabolol on rotenone-induced toxicity in Drosophila melanogaster

Gerlânia de Oliveira Leite ${ }^{\mathrm{a}}$, Assis Ecker ${ }^{\mathrm{b}}$, Rodrigo Lopes Seeger ${ }^{\mathrm{b}}$, Bárbara Nunes Krum $^{\text {b }}$, Thiago Henrique Lugokenski ${ }^{\mathrm{c}}$, Roselei Fachinetto ${ }^{\mathrm{a}}$, Jéssie Haigert Sudati ${ }^{\mathrm{c}}$, Nilda Vargas Barbosa ${ }^{\mathrm{b}}$ and Caroline Wagner ${ }^{\mathrm{a}, \mathrm{c}^{*}}$

${ }^{a}$ Programa de Pós-Graduação em Farmacologia, Universidade Federal de Santa Maria, Santa Maria - RS, Brazil.

${ }^{b}$ Programa de Pós-Graduação em Ciências Biológicas - Bioquímica Toxicológica, Universidade Federal de Santa Maria, Santa Maria-RS, Brazil.

${ }^{c}$ Universidade Federal do Pampa, Campus Caçapava do Sul, Caçapava do Sul - RS, Brazil.

*Corresponding author. Tel.: +55 (55) 32819000

E-mail address: wagnercarolwagner@gmail.com

\begin{abstract}
(-)- $\alpha$-Bisabolol (BISA) is a sesquiterpene alcohol, which has with several recognized biological activities, including anti-inflammatory, anti-irritant, and antibacterial properties. In the present study, we investigated the influence of BISA $(5,25$, and 250 $\mu \mathrm{M})$ on rotenone $(500 \mu \mathrm{M})$-induced toxicity in Drosophila melanogaster for 7 days. BISA supplementation significantly decreased rotenone-induced mortality and locomotor deficits. The loss of motor function induced by rotenone correlated with a
\end{abstract}


significant change in stress response factors; it decreased thiol levels, inhibited mitochondria complex I, and increased the mRNA expression of antioxidant marker proteins such as superoxide dismutase (SOD), catalase (CAT), and the keapl gene product. Taken together, our findings indicate that the toxicity of rotenone is likely due to the direct inhibition of complex I activity, resulting in a high level of oxidative stress. Dietary supplementation with BISA affected the expression of SOD mRNA only at a concentration of $250 \mu \mathrm{M}$, and did not affect any other parameter measured. In conclusion, our results showed a protective effect of BISA on rotenone-induced mortality and locomotor deficits in Drosophila; this effect did not correlate with mitochondrial complex I activity, but may be related to the antioxidant protection afforded by eliminating superoxide generated as a result of rotenone-induced mitochondrial dysfunction.

Keywords: Drosophila melanogaster, (-)- $\alpha$-bisabolol, oxidative stress, rotenone.

\section{Introduction}

(-)- $\alpha$-Bisabolol (BISA), a volatile monocyclic sesquiterpene alcohol, is a naturally occurring constituent of the essential oil of several plants of the Asteraceae family. BISA is widely used in dermatological and cosmetic formulations (GomesCarneiro et al. 2005). BISA also displays various biological activities, such as antitumor activity (Darra et al. 2008; Silva et al., 2010), inhibition of peripheral nerve conduction (Alves et al. 2010), blockade of $\mathrm{Ca}^{2+}$ (Siqueira et al. 2012) and $\mathrm{K}^{+}$channels (Bezerra et al. 2009), gastroprotection (Bezerra et al. 2009; Rocha et al. 2010, 2011a), antinociceptive and ant-inflammatory activities (Leite et al. 2011, 2012; Rocha et al. 2011b), leishmanicidal activity (Morales et al. 2010), antioxidant activity (Braga et al. 
2009; Rocha et al. 2011a; Leite et al. 2016), antimutagenic activity (Gomes-Carneiro et al. 2005), wound healing properties (Villegas et al. 2001), and inhibitory actions on $\alpha 7-$ nicotinic acetylcholine receptors (Nurulain et al. 2015). Based on this broad spectrum of effects and due to its protective effects against diverse chemical and biological insults, BISA may be a potential neuroprotectant, among its many other functions.

Chronic, systemic exposure to rotenone has been used in animals to model Parkinson's Disease (Betarbet et al. 2000). Rotenone, a widely used natural pesticide, is a complex ketone derived from the roots of Lonchocarpus species, and is a high affinity specific inhibitor of mitochondrial NADH dehydrogenase (complex I) (Uversky 2004). Exposure of adult Drosophila to sublethal doses of rotenone in the diet over 7 days causes concentration-dependent locomotor deficits, dopaminergic specific neuronal loss, and a reduction in dopamine levels in adult flies (Coulom and Birman 2004).

The rotenone-based model has been broadly and successfully used by researchers to screen putative neuroprotective phytochemicals (Chaudhuri et al. 2007; Ravikumar et al. 2009; 2010; Sudati et al. 2013). In addition to disrupting electron transport by inhibiting mitochondrial complex I, rotenone causes oxidative damage in mitochondria that correlates with reduced SOD activity (Sherer et al. 2003; Cannon et al. 2009).

Drosophila melanogaster is the invertebrate organism closest to humans, based on gene sequence similarity and conservation (Rubin et al. 2000; Bier et al.2005). Drosophila are highly sensitive to toxic substances and are considered a useful model for identifying pollutants as well as for evaluating the biological action of pharmacological agents. In fact, Drosophila have been recommended by the European Centre for the Validation of Alternative Methods (ECVAM) as promoting the 3Rs 
(reduction, refinement, and replacement) of laboratory animal use in toxicity and testing studies (Benford et al. 2000). D. melanogaster have been effectively used to investigate the underlying mechanisms in the pathophysiology of numerous neurological and nonneurological human diseases (Nichols 2006; Pandley et al. 2011; Adedara et al. 2015) and are widely used to assess the therapeutic potential of phytochemicals.

Based on our findings on the antioxidant activity of BISA (Leite et al. 2016), we hypothesized that BISA could prove to be protective in neurotoxicity models. Therefore, we used rotenone-induced toxicity in a D. melanogaster as our test model. In the present investigation, we examined the ability of BISA to modulate rotenoneinduced death, locomotor deficits, induction of antioxidant biomarkers, and mitochondrial dysfunction in D. melanogaster.

\section{Materials and Methods}

\subsection{Drosophila stock}

D. melanogaster (Harwich strain) used in the present investigation were obtained from the National Species Stock Center (Bowling Green, OH, USA). The flies were reared in vials containing $3 \mathrm{~mL}$ agar medium $(2 \%$, w/v sucrose; $1 \%$, w/v brewer's yeast; $1 \%$, w/v powdered milk; $1 \%$, w/v agar; $0.08 \%$, v/w nipagin) at constant temperature and humidity $\left(23 \pm 1{ }^{\circ} \mathrm{C}\right.$ and $60 \%$ relative humidity, respectively) with a 12-hour light and dark cycle. All experiments were performed using the same strain.

\subsection{Experimental Procedure}

\subsubsection{Rotenone Exposure and (-)- $\alpha$-Bisabolol Treatment}


Flies (1-2 days old, male and female) were divided into eight groups: (1) control; (2) rotenone $(500 \mu \mathrm{M}) ;(3,4$, and 5) BISA $(5,25$, and $250 \mu \mathrm{M}$, respectively); and $(6,7$, and 8) $\operatorname{BISA}(5,25$, and $250 \mu \mathrm{M}$, respectively) plus rotenone $(500 \mu \mathrm{M})$. Rotenone (dissolved in ethanol 98\%) and BISA were added into the fly food. The volume of ethanol in the food was limited to $1 \%$. Two controls were used (with and without ethanol). However, only the ethanol control is shown in the results because there was no statistical difference among the groups for any of the parameters evaluated. The flies were exposed to the treated food for 7 days (Sudati et al. 2013) and the vials maintained in an incubator at $23 \pm 1{ }^{\circ} \mathrm{C}$ until being processed for various assays. The BISA concentrations were based on previous observations showing that BISA in the range of 5-500 $\mu \mathrm{M}$ did not cause overt signs of toxicity to flies (data not shown).

\subsubsection{Survival Rate}

The vials were scored daily for mortality. The survival rate was based on the living fly count each day over the 7-day experimental period, and the survivors were transferred to freshly prepared food. The number of flies in the final calculation represents the sum of three independent experiments (25 flies/treatment/repetition).

\subsubsection{Negative Geotaxis Assay}

The locomotor activity of flies was determined based on negative geotaxis behavioral assay (climbing) as previously described by Feany and Bender (2000) with some modifications. The flies (both sexes) were immobilized by brief cold exposure, sorted, and placed in a vertical glass column tube $(15 \mathrm{~cm}$ long and $1.5 \mathrm{~cm}$ in diameter $)$. After they recovered (approximately $20 \mathrm{~min}$ ), the flies were gently tapped to the bottom of the 
column. The flies that reached the top portion of the column $(6 \mathrm{~cm})$ and the flies that remained at the bottom were counted separately over $6 \mathrm{~s}$. The scores represent the mean of the numbers of flies at the top $\left(\mathrm{n}_{\text {top }}\right)$ as percentage of the total number of flies $\left(\mathrm{n}_{\mathrm{tot}}\right)$. About 10 flies per group from three independent experiments were included in the negative geotaxis assay (30 flies).

\subsubsection{Quantitative Real-Time RT-PCR and Gene Expression Analysis}

Approximately $2 \mu \mathrm{g}$ of total RNA from 25 young flies was extracted using TRIzol® Reagent (Invitrogen ${ }^{\mathrm{TM}}$ ), according to the manufacturer's suggested protocol. After quantification, total RNA was treated with DNase I (Invitrogen ${ }^{\mathrm{TM}}$ ) and cDNA amplified with M-MLV reverse transcriptase enzyme and random primers according to the manufacturer's suggested protocol (Invitrogen ${ }^{\mathrm{TM}}$ ). Quantitative real-time polymerase chain reaction was performed in $20 \mu \mathrm{L}$ reaction volumes containing $1 \mathrm{x}$ PCR buffer, 25 $\mu \mathrm{M}$ dNTPs, $0.2 \mu \mathrm{M}$ of each primer (described in Table I), $1.5-2.5 \mathrm{mM} \mathrm{MgCl} 2,0.1 \mathrm{x}$ SYBR Green I (Invitrogen ${ }^{\mathrm{TM}}$, Molecular Probes $^{\mathrm{TM}}$ ), and $1 \mathrm{U}^{\text {Platinum }}{ }^{\circledR}$ Taq DNA polymerase (Invitrogen ${ }^{\mathrm{TM}}$ ) by using StepOnePlus real time PCR systems (Applied Biosystems). The following parameters were used in the qPCR protocol: activation of the Taq DNA polymerase at $95^{\circ} \mathrm{C}$ for $5 \mathrm{~min}$, followed by 40 cycles of $15 \mathrm{~s}$ at $95^{\circ} \mathrm{C}, 15 \mathrm{~s}$ at $60{ }^{\circ} \mathrm{C}$, and $25 \mathrm{~s}$ at $72{ }^{\circ} \mathrm{C}$. All samples were analyzed in triplicate as both technical and biological replicates and a negative control was included. Threshold and baselines were manually determined using the StepOne Software 2.0 (Applied Biosystems). SYBR fluorescence was analyzed by StepOne software version 2.0 (Applied Biosystems), and the CT (cycle threshold) value for each sample was calculated and reported using the $2^{-}$ ${ }^{\Delta \Delta C T}$ method (Livak and Schmittgen, 2001). The actin genes were used as endogenous 
reference genes presenting no alteration in response to the treatment. For each well, analyzed in triplicate, a $\Delta \mathrm{C}_{\mathrm{T}}$ value was obtained by subtracting the actin $\mathrm{CT}$ value from the CT value for the gene of interest (sequences of tested genes are represented in Table I). The mean $\Delta \mathrm{C}_{\mathrm{T}}$ value obtained from the control group for each gene was used to calculate the $\Delta \Delta \mathrm{C}$ of the respective gene $\left(2^{-\Delta \Delta \mathrm{CT}}\right)$.

\subsubsection{Thiol Determination}

The total thiol content was determined based on a spectrophotometric method using Ellman's reagent, DTNB (5,5'-dithiobis-(2-nitrobenzoic acid).

\subsubsection{Mitochondrial Complex I}

\subsubsection{Preparation of Drosophila melanogaster Mitochondria}

The treated D. melanogaster were homogenized in a Potter homogenizer in homogenization medium (250 mM sucrose, $5 \mathrm{mM}$ Tris- $\mathrm{HCl}, 2 \mathrm{mM}$ EGTA, 0.1\% albumin $\mathrm{pH}$ 7.4). The homogenate was centrifuged at $1,000 \mathrm{~g}$ for $3 \mathrm{~min}$ at $4{ }^{\circ} \mathrm{C}$, and the supernatant fraction was then centrifuged at $12,000 \mathrm{~g}$ for $10 \mathrm{~min}$ to pellet the mitochondria, which were washed once by resuspension and centrifugation under identical conditions (Miwa et al. 2003). Total protein content was adjusted to $20 \mathrm{mg} / \mathrm{mL}$ (Peterson, 1977), and the samples were immediately frozen and kept at $-80^{\circ} \mathrm{C}$.

\subsubsection{Mitochondrial Complex Activity Assay}

The activity of complex I was determined spectrophotometrically at $30{ }^{\circ} \mathrm{C}$ using mitochondria prepared as above and suspended in $100 \mathrm{mM}$ phosphate buffer (pH 7.4) as previously described (Navarro et al. 2002, 2004). The reaction was initiated by addition 
of NADH at a final concentration of $100 \mu \mathrm{M}$, and the enzymatic activity was determined by following the decrease in absorbance at $340 \mathrm{~nm}$ (Puntel et al. 2013).

\subsubsection{Western Blot Analysis of tyrosine hydroxylase}

Flies were homogenized at $4{ }^{\circ} \mathrm{C}$ in $500 \mu \mathrm{L}$ of lysis buffer ( $4 \%$ sodium dodecyl sulfate (SDS), $2 \mathrm{mM}$ EDTA, $50 \mathrm{mM}$ Tris, $0.5 \mathrm{mM}$ sodium orthovanadate, $2 \mu \mathrm{g} / \mathrm{mL}$ aprotinin, $0.1 \mathrm{mM}$ benzamidine, $0.1 \mathrm{mM}$ PMSF). Samples were boiled for $6 \mathrm{~min}$ and centrifuged at $1.000 \mathrm{~g}$ at $4{ }^{\circ} \mathrm{C}$ for $10 \mathrm{~min}$. The protein concentration was determined in the supernatant fraction using the method of Lowry. The samples were then mixed with $25 \%$ glycerol and $8 \%$ 2-mercaptoethanol and resolved by $10 \%$ SDS-PAGE. Aliquots of the samples were transferred onto a nitrocellulose membrane (Millipore, USA). The membrane was stained for protein using Ponceau solution $(0.5 \%$ Ponceau plus $5 \%$ glacial acetic acid in water), to monitor loading (Romero-Calvo et al. 2010). After staining, the membranes were dried and protein quantified by scanning. The membranes were then processed, blocked with $1 \%$ bovine serum albumin, and incubated overnight with an anti tyrosine hydroxylaxe antibody (1:10000; Millipore). Thereafter, the membranes were incubated with alkaline phosphatase-coupled secondary antibody (1:10000; Millipore, USA). The amount of enzyme present was determined by following the reaction colorimetrically using nitro blue tetrazolium (NBT)/5-bromo-4chloro-3-indolyl phosphate (BCIP) as a substrate (Trevisan et al. 2013) and the values were normalized to the protein concentration based on that determined by Ponceau staining.

\subsubsection{Statistical Analysis}


Statistical analysis was performed using statistical analysis for censored data: Log rank (Mantel - Cox) test to survival curve, or one-way ANOVA, followed by NewmanKeuls Multiple test for another results. The difference among the groups was considered to be significant when $\mathrm{p}<0.05$.

\section{Results}

\section{Effect of (-)-a-Bisabolol on the Survival of Flies Exposed to Rotenone}

Log - rank Test demonstrated that survival curves are significant different, with $\mathrm{p}<$ 0.001. Acute exposure to rotenone caused an increase in the mortality of flies when compared to the no treatment (control) group. BISA treatment offered protection, at all concentrations tested (Figure 1). Further, the BISA $(5,25$, and $250 \mu \mathrm{M})$ only treated groups did not show any difference from the no treatment control group.

\section{Effects of (-)- $\alpha$-Bisabolol on Rotenone-induced Locomotor Deficits}

Rotenone treated flies exhibited severe motor impairment, and BISA significantly improved the performances of flies in the negative geotaxis test. In general, flies treated with added BISA appeared to be more active than rotenone alone treated flies. Further, BISA alone had no significant effect on motor behavior among the groups of flies (Figure 2).

Effect of Rotenone and (-)- $\alpha$-Bisabolol on CAT, SOD, and KEAP1 mRNA

\section{Expression}

Rotenone exposure caused a significant increase in the mRNA expression of genes for catalase (2 fold) (Figure 3A), superoxide dismutase (2.6 fold) (Figure 3B), and Keap-1 
(1.7 fold) (Figure 3C). BISA significantly reduced SOD mRNA expression only at the $250 \mu \mathrm{M}$ concentration (Figure 3B).

Effect of (-)- $\alpha$-Bisabolol on Thiol Content in Homogenates of Flies Exposed to Rotenone

Rotenone exposure significantly reduced the total thiol content in flies as compared to the control group (Figure 4). The presence of BISA was not found to ameliorate the effect of rotenone on thiol content.

\section{Effect of (-)- $\alpha$-Bisabolol on Complex I Activity of Flies Exposed to Rotenone}

BISA alone had no effect on complex I activity as compared to that in the control group. However, among the groups of rotenone treated flies, significant inhibition was evident. Furthermore, the activity level of complex I was not different in groups of flies concurrently treated with BISA than that in groups treated with rotenone alone (Figure $5)$.

\section{Effect of (-)- $\alpha$-Bisabolol on Cell Signaling}

We evaluated the expression of the target protein involved in dopaminergic system signaling, tyrosine hydroxylase $(\mathrm{TH})$, as a possible mechanism of BISA action. As demonstrated in Figure 6, BISA produced no change in the expression of TH compared to that in the control group. Furthermore, the basal levels of TH remained unaltered in groups of flies exposed to the rotenone and treated concurrently with BISA (Figure 6). 


\section{Discussion}

Using Drosophila as a model system of neurological damage, our data show significant protective effects of BISA against mortality and locomotor deficits elicited by rotenone. Our previous findings had led us to hypothesize that BISA was potentially counteracting the well documented toxicity mechanism related to rotenone, namely inhibition of complex I activity followed by oxidative stress-mediated cell death (Uversky 2004; Sherer et al. 2003; Cannon et al. 2009).

There are a large number of articles in the literature that have used this animal model for rotenone toxicity testing, which reinforces that the rotenone toxicity test model in Drosophila is widely accepted and use (Rao et al. 2016; Vargas et al. 2014; Hwang et al. 2014; Ravikumar et al. 2010; Lawal et al. 2010). In adittion, Drosophila has a short generation time (10 days) and life span (60-80 days). The complete sequence of the Drosophila genome has revealed that $77 \%$ of human disease genes are conserved in the fly (Rubin 2000; Bier 2005). These features make flies an excellent model system in which to study the function of disease genes including those involved in neurodegenerative diseases (Lessing and Bonini 2009; Lu and Vogel 2009). It is a well known for its high sensitivity to toxic substances and is being considered a model for detection of pollutants and widely employed as a model to assess the therapeutic potential of phytochemicals.

To follow up, we focused the present investigation on specific molecular/biochemical pathways in an attempt to better elucidate the mechanism by which BISA may block the deleterious effects of the pesticide. As expected, rotenone strongly inhibited complex I activity. Moreover, we found evidence that flies treated with rotenone mounted a response to oxidative stress, as evidenced by the increase of 
catalase, SOD and Keap I mRNA expression. Unfortunately, despite the initial observation that dietary BISA is protective against rotenone-induced toxicity in flies, we found no clear correlation with complex I inhibition or oxidative stress when flies were given rotenone and BISA concurrently. On the contrary, these findings may indicate an unknown property of BISA for future investigation. We are currently exploring several possibilities.

Rotenone is a lipophilic compound that freely crosses cell membranes and can access both the cytoplasmic and mitochondrial compartments. Its research use has grown exponentially over the last few years largely due to the discovery of its ability to reproduce many features of PD in rats, including development of $\alpha$-synuclein-positive cytoplasmic inclusions, which are similar to Lewy bodies found in nigral neurons in human PD patients (Betarbet et al. 2000). Inhibition of mitochondrial respiratory chain complex I by rotenone has been found to induce cell death in a variety of cells, as well as cause reactive oxygen species (ROS) generation.

The present research demonstrated that rotenone exposure significantly increased the mortality of flies. This observation is supported by findings of previous studies where rotenone caused high mortality among flies during a 7-day exposure period (Ravikumar et al. 2009, 2010; Sudati et al. 2013). However, supplementation of BISA in the diet reversed the rotenone-mediated toxicity and decreased mortality.

In addition, rotenone induced toxicity is accompanied by a high rate of locomotor deficits, and concurrent exposure to BISA significantly improved the performances of flies in the negative geotaxis test. Flies with locomotor deficits have the tendency to stay at the bottom of a glass column and appear not to be able to coordinate their legs in a normal fashion. This behavior has been explained by severe 
complex I inhibition. High energy expenditure is a requirement of ambulatory and flight muscles, but rotenone exposure can cause loss in complex I activity (Figure 5) leading to a decrease in the rate of energy production as well as causing increased oxidative stress at the mitochondrial membrane. Ravikumar (2009) attribute the locomotor deficits caused in rotenone-exposed flies to uncoupling of the mitochondrial machinery (severe damage in complex I) and neurodegeneration. In the insect, rotenone induced neurotoxicity is attributed to the unique sensitivity of dopaminergic neurons to reactive oxygen species and oxidative damage. In our work, rotenone caused complex I activity loss, however, its effects on the dopaminergic system was not clear, and, although BISA protected against the effects of rotenone, its mechanism of action is also unclear. We suggest that it is related to its ability to counteract free radicals produced as a result of the damage to complex I.

In previous studies, flies exposed to rotenone had significantly elevated levels of antioxidant enzymes, and that correlated to the increased ROS generation and formation of toxic aldehydes (Ravikumar et al. 2009 and 2010). Excessive ROS generation can cause lipid peroxidation; mitochondrial dysfunction; and damage to proteins, lipids, and nucleic acids; thereby, altering normal functions of the cell (Valko et al. 2007) and lead to cell death and mortality of the host. Thus, excessive ROS generation can be related to rotenone-induced loss of complex I activity. Complex I, also known as NADHubiquinone oxidoreductase, is the first step in the transfer of electrons from NADH to the electron-transport chain during biochemical respiration. Rotenone uncouples electron transport at the complex I site leading to ROS production (Cassarino et al., 1997; Barrientos and Moraes, 1999; Kushnareva et al., 2002). Our data demonstrated that rotenone inhibited complex I, however, BISA failed to protect against loss of 
activity. Apparently, instead BISA counteracts the effects of ROS generation when complex I is inhibited by rotenone. Thus, BISA ameliorates the downstream damage through an antioxidant mechanism.

In additional experiments, we observed that rotenone increased CAT, SOD and keapl mRNA expression, which may represent a compensatory response to oxidative insults. The Keap1-Nrf2 pathway is the major regulator of cytoprotective responses to endogenous and exogenous stress caused by various oxidants and electrophilic agents. Keap1 is a repressor protein that binds to Nrf2 and promotes its degradation. Furthermore, Nrf2-bound Keap1 is inactivated. Nrf2 augments a wide range of cell defense processes, thereby enhancing the overall capacity of cells to detoxify potentially harmful molecular assaults (Kansanen et al. 2012). Additionally, Satoh et al (2009) showed that cortical neurons with keapl gene-knockout, exhibited increased resistance to oxidative stress induced by high concentrations of glutamate and rotenone. In those studies, rotenone increased keapl mRNA expression (Figure 3C), leading to Nrf2 inactivation, and consequently decreasing the ability to resist oxidative stress, the inability to detoxify harmful molecules, and, generally, lowering cell defenses.

The elevated expression of SOD mRNAs by rotenone was normalized by BISA treatment. Our data also corroborate previous studies showing that BISA-induced gastroprotection is associated with increased SOD activity (Rocha et al. 2011a). The effects of BISA on the usual oxidative stress markers indicate that it works through an antioxidant mechanism. Thus, the decrease in SOD mRNA expression may be related to the ability of BISA to scavenge rotenone-induced superoxide thereby removing the signals leading to SOD expression. This further suggests that BISA exerts its protective effect by counteracting superoxide anion generated by rotenone-damaged mitochondria. 
Another mechanism of toxicity of rotenone is dopaminergic neuronal loss and reduction in the dopamine levels in adult flies (Coulom and Birman 2004). Therefore, we evaluated the expression of the key protein involved in dopaminergic system signaling, tyrosine hydroxylase (TH). In our work, the levels of TH remained unaltered in flies exposed to the rotenone and with or without BISA treatment. This result is similar to that observed by Navarro et al. (2014), showing that acute rotenone treatment (500 $\mu \mathrm{M}$ for 6 days) leads to a neurodegeneration, as evidenced by a decrease in a reporter green-fluorescent protein (GFP) signal in dopaminergic neurons, without affecting the total number of dopaminergic neurons, but suggesting an abnormal neuronal status.

\section{Conclusion}

In conclusion, the presence of BISA protects against rotenone-induced toxicity as evidenced by markedly decreasing mortality, preventing locomotor activity deficits, and normalizing expression of SOD mRNA. The protective effect of BISA was likely associated with its free radical scavenging and antioxidant actions. BISA can be used to counteract toxicity due to an environmental toxin such as rotenone. Additional experiments are necessary to clarify the mechanism of action of BISA. 


\section{References}

Adedara, I.A., Klimaczewski, V.C., Souza, D.O., Barbosa, N.B.V., Farombi, E.O., Souza, O.D., Rocha, J.B.T. 2015. Influence of diphenyl diselenide on chlorpyrifosinduced toxicity in Drosophila melanogaster. J. Trace Elem. Med. Biol. 32: 52-59.

Alves, A.M., Gonçalves, J.C., Cruz, J.S., Araújo, D.A. 2010. Evaluation of the sesquiterpene (-)-alpha-bisabolol as a novel peripheral nervous blocker. Neurosci. Lett. 472(1): 11-15.

Barrientos, A., Moraes, C.T., 1999. Titrating the effects of mitochondrial complex I impairment in the cell physiology. J. Biol. Chem. 274, 16188-16197.

Benford, D.J., Hanley, A.B., Bottrill, K., Oehlschlager, S., Balls, M., Brance, F., Castegnara, J.J., Descotes, J., Hemminiky, K., Lindsay, D., Schilter, B. 2000. Biomarkers as predictive tools in toxicity testing. The Report and Recommendations of ECVAM Workshop 40. Alternatives to Laboratory Animals. 28: 119-31. 
Betarbet, R., Shere, T.B., Mackenzie, G., Garcia-Osuna, M., Panov, A.V., Geenamyre, J.T. 2000. Chronic systemic pesticide exposure reproduces features of Parkinson's disease. Nature Neurosci. 3: 1301-1306.

Bezerra, S.B., Leal, L.K., Nogueira, N.A., Campos, A.R. 2009. Bisabolol-induced gastroprotection against acute gastric lesions: role of prostaglandins, nitric oxide, and KATP+ channels. J. Med. Food. 12(6): 1403-1406.

Bier, E. 2005. Drosophila, the golden bug, emerges as a tool for human genetics. Nature Rev. Genet. 6: 9-23.

Braga, P.C., Dal Sasso, M., Fonti, E., Culici, M. 2009. Antioxidant activity of bisabolol: inhibitory effects on chemiluminescence of human neutrophil bursts and cell-free systems. Pharmacology. 83(2): 110-115.

Cannon, J.R., Tapias, V., Na, H.M., Honick, A.S., Drolet, R.E., Greenamyre, J.T. 2009. A highly reproducible rotenone model of Parkinson's disease. Neurobiol. Dis. 34: 279_ 290.

Cassarino, D.S., Fall, C.P., Swerdlow, R.H., Smith, T.S., Halvorsen, E.M., Miller, S.W., Parks, J.P., Parker, W.D.Jr., Bennett, J.P. Jr., 1997. Elevated reactive oxygen species and antioxidant enzyme activities in animal and cellular models of Parkinson's disease. Biochimica et Biophysica Acta. 1362: 77-86. 
Chaudhuri, A., Bowling, K., Funderburk, C., Lawal, H., Inamdar, A., Wang, Z. et al. 2007. Interaction of genetic and environmental factors in a Drosophila Parkinsonism model. Journal Neurosci. 27: 2457-67.

Coulom, H., Birman, S. 2004. Chronic exposure to rotenone models sporadic Parkinson's disease in Drosophila melanogaster. Journal Neurosci. 24: 10993-8.

Darra, E., Abdel-Azeim, S., Manara, A., Shoji, K., Marechal, J.D., Mariotto, S., Cavalieri, E., Perbellini, L., Pizza, C., Perahia, D., Crimi, M., Suzuki, H. 2008. Insight into the apoptosis-inducing action of alphabisabolol towards malignant tumor cells: involvement of lipid rafts and Bids, Arch. Biochem. Biophys. 476: 113-123.

Ellman, G.L. 1959. Tissue sulfhydryl groups. Arch. Biochem. Biophys. 82: 70-7.

Feany, M.B., Bender, W.W. 2000. A Drosophila model of Parkinson's disease. Nature. 404: 394-398.

Gomes-Carneiro, M.R., Dias, D.M., De-Oliveira, A.C., Paumgartten, F.J. 2005. Evaluation of mutagenic and antimutagenic activities of alpha-bisabolol in the Salmonella=microsome assay, Mutat Res (Full Set). 585: 105-112. 
Hwang, R.D., Wiemerslage, L., LaBreck, C.J., Khan, M., Kannan, K., Wang, X., Zhu, X., Lee, D., Fridell, Y.W. 2014. The neuroprotective effect of human uncoupling protein 2 (hUCP2) requires cAMP-dependent protein kinase in a toxin model of Parkinson's disease. Neurobiol. Dis. 69:180-91.

Kansanen, E., Jyrkkänen, H.K., Levonen A.L. 2012. Activation of stress signaling pathways by electrophilic oxidized and nitrated lipids. Free Radic. Biol. Med. 52: 973982.

Kushnareva, Y., Murphy, A.N., Andreyev, A., 2002. Complex I-mediated reactive oxygen species generation: modulation by cytochrome $\mathrm{c}$ and $\mathrm{NAD}(\mathrm{P})+$ oxidationreduction state. Biochemical Journal. 368: 545-553.

Lawal, H.O., Chang, H.Y., Terrell, A.N., Brooks, E.S., Pulido, D., Simon, A.F., Krantz, D.E. 2010. The Drosophila vesicular monoamine transporter reduces pesticide-induced loss of dopaminergic neurons. Neurobiol. Dis. 40(1):102-12.

Leite, G.O., Dubois, A.F., Seeger, R.L., Boligon, A.A., Costa, J.G.M., Lugokenski, T.H., Campos, A.R., Fachinetto, R., Kamdem, J.P., Rocha, J.B.T., Wagner, C. 2016. In vitro antioxidant activity investigation of Vanillomopsis arborea Baker aqueous extracts, essential oil and isolated compound: (-)-alfa-bisabolol. Pharmacologia. 7(4): 193-201. DOI: 10.5567/pharmacologia.2016.193.201. 
Leite, G.O., Fernandes, C.N., Menezes, I.R.A., Costa, J.G.M., Campos, A.R. 2012. Attenuation of visceral nociception by alpha-bisabolol in mice: investigation of mechanisms. Org. Med. Chem. Letters. 2: 01-03.

Leite, G.O., Leite, L.H.I., Sampaio, R.S., Araruna, M.K.A., Menezes, I.R.A., Costa, J.G.M., Campos, A.R. 2011. (-)- $\alpha$-Bisabolol attenuates visceral nociception and inflammation in mice. Fitoterapia. 82: $208-211$.

Lessing, D., Bonini, N.M. 2009. Maintaining the Brain: Insight into Human Neurodegeneration From Drosophila Mutants. Nat. Rev. Genet. 10(6): 359.

Livak, K.J., Schmittgen, T.D. 2001. Analysis of relative gene expression data using real-time quantitative PCR and the 2( - Delta Delta C(T)) method. Methods. 25: 402-8.

Lu, B., Vogel, H. 2009. Drosophila models of neurodegenerative diseases. Annu Rev. Pathol. 4:315-42.

Miwa, S., St-Pierre, J., Partridge, L., Brand, M.D., 2003. Superoxide and hydrogenperoxide production by Drosophila mitochondria. Free Radic. Biol. Med. 35: $938-948$.

Morales-Yuste, M., Morillas-Márquez, F., Martín-Sánchez, J., Valero-López, A., Navarro-Moll, M.C. 2010. Activity of (-)alpha-bisabolol against Leishmania infantum promastigotes. Phytomedicine. 17: 279-281. 
Navarro, A., Gomez, C., Lopez-Cepero, J.M., Boveris, A. 2004. Beneficial effects of moderate exercise on mice aging: survival, behavior, oxidative stress, and mitochondrial electron transfer. Am. J. Physiol. Regul. Integr. Comp. Physiol. 286(3): R505-R511.

Navarro, A., Sanchez Del Pino, M.J., Gomez, C., Peralta, J.L., Boveris, A. 2002. Behavioral dysfunction, brain oxidative stress, and impaired mitochondrial electron transfer in aging mice. Am. J. Physiol. Regul. Integr. Comp. Physiol. 282(4): R985R992.

Navarro, J.A., Heßner, S., Yenisetti, S.C., Bayersdorfer, F., Zhang, L., Voigt, A., Schneuwly, S., Botella, J.A. 2014. Analysis of dopaminergic neuronal dysfunction in genetic and toxin-induced models of Parkinson's disease in Drosophila. J. Neurochem. 131(3):369-82.

Nilchols, C.D. 2006. Drosophila melanogaster neurobiology, neuropharmacology, and how the fly can inform central nervous system drug discovery. Pharmacol. Ther. 112: $677-700$.

Nurulain, S., Prytkova, T., Sultan, A.M., Levglevskyi, O., Lorke, D., Yang, K.H.S., Petroianu, G., Howarth, F.C., Kabbani, N., OZ, M. 2015. Inhibitory actions of bisabolol on $\alpha 7$-nicotinic acetylcholine receptors. Neuroscience. 306: 91-99.

Pandey, U.B., Nichols, C.D. 2011. Human Disease Models in Drosophila melanogaster and the Role of the Fly in Therapeutic Drug Discovery. Pharmacol. Rev. 63: 411-436. 
Peterson, G.L. 1977. A simplification of the protein assay method of Lowry et al. which is more generally applicable. Anal Biochem. 83(2): 346-356.

Puntel, R.L., Roos, D.H., Seeger, R.L., Aschner, M., Rocha, J.B.T. 2013. Organochalcogens Inhibit Mitochondrial Complexes I and II in Rat Brain: Possible Implications for Neurotoxicity. Neurotox. Res. 24: 109-118.

Rao, S.V., Muralidhara, Yenisetti, S.C., Rajini, P.S. 2016. Evidence of neuroprotective effects of saffron and crocin in a Drosophila model of parkinsonism. Neurotoxicology. 52: $230-42$.

Ravikumar, H., Muralidhara. 2009. Neuroprotective efficacy of Bacopa monnieri against rotenone induced oxidative stress and neurotoxicty in Drosophila melanogaster. NeuroToxicology. 30: 977-985.

Ravikumar, H., Ramesh, S.R., Muralidhara. 2010. Attenuation of Rotenone-Induced Mitochondrial Oxidative Damage and Neurotoxicty in Drosophila melanogaster Supplemented with Creatine. Neuroch. Res. 35: 1402-1412.

Rocha, N.F.M., Oliveira, G.V., Araújo, F.Y.R., Rios, V.E.R., Carvalho, A.M.R., Vasconcelos, L.F., Macêdo, D.S., Soares, P.M.G., Sousa, D.P., Sousa, F.C.F. 2011a. (-)$\alpha$-Bisabolol-induced gastroprotection is associated with reduction in lipid Peroxidation, superoxide dismutase activity and neutrophil migration. Eur. J. Pharm. Sci. 44: 455461. 
Rocha, N.F.M., Rios, E.R.V., Carvalho, A.M.R., Cerqueira, G.S., Lopes, A.A., Leal, L.K.A.M., Dias, M.L., Sousa, D.P., Sousa, F.C.F. 2011b. Anti-nociceptive and antiinflammatory activities of (-)- $\alpha$-bisabolol in rodents. Naunyn-Schmiedeberg's Arch. Pharmacol. 384: 525-533.

Rocha, N.F.M., Venâncio, E.T., Moura, B.A., Silva, M.I.G., Aquino Neto, M.R., Rios, V.E.R., Sousa, D.P., Vasconcelos, S.M.M., Fonteles, M.M.F., Sousa, F.C.F. 2010. Gastroprotection of (-)- $\alpha$-bisabolol on acute gastric mucosal lesions in mice. The possible involved pharmacological mechanisms. Fund. Clin. Pharmacol. 24: 63-71.

Romero-Calvo, I., Ocon, B., Martinez-Moya, P., Suarez, M.D., Zarzuelo, A., MartinezAugustin, O., Medina, F.S. 2010. Reversible Ponceau staining as a loading control alternative to actin in Western blots. Anal Biochem. 401: 318-320.

Rubin, G.M., Lewis, E.B. 2000. A brief history of Drosophila's contributions to genome research. Science. 287: 2216-2218.

Satoh, T., Harada, N., Tomonori, Hosoya, T., Tohyama K., Yamamoto, M., Itoh, K.. 2009. Keap1/Nrf2 system regulates neuronal survival as revealed through study of keap1 gene-knockout mice. Biochem. Biophys. Res. Commun. 380(2): 298-302. 
Sherer, T.B., Betarbet, R., Testa, C.M., Seo, B.B., Richardson, J.R., Kim, J.H., Miller, G.W., Yagi, T., Matsuno-Yagi, A., Greenamyre, J.T. 2003. Mechanism of toxicity in rotenone models of Parkinson's disease. Journal Neurosci. 23: 10756-10764.

Silva, A.P., Martini, M.V., de Oliveira C.M., Cunha, S., de Carvalho, J.E., Ruiz, A.L., da Silva, C.C. 2010. Antitumor activity of (-)-alpha-bisabolol-based thiosemicarbazones against human tumor cell lines. Eur. J. Pharm. Sci. 45 (7): 29872993.

Siqueira, R.J., Freire, W.B., Vasconcelos-Silva, A.A., Fonseca-Magalhães, P.A., Lima, F.J., Brito, T.S., Mourão, L.T., Ribeiro, R.A., Lahlou, S., Magalhães, P.J. 2012. In-vitro characterization of the pharmacological effects induced by (-)- $\alpha$-bisabolol in rat smooth muscle preparations. Can. J. Physiol. Pharmacol. 90: 23-35.

Sudati, J.H., Vieira, F.A., Pavin, S.S., Dias, G.R.M., Seeger, R.L., Golombieski, R., Athayde, M.L., Soares, F.A., Rocha, J.B.T., Barbosa, N.V. 2013. Valeriana officinalis attenuates the rotenone-induced toxicity in Drosophila Melanogaster. NeuroToxicology. 37: $118-126$.

Trevisan, G., Hoffmeister, C., Rossato, M.F., Oliveira, S.M., Silva, M.A., Ineu, R.P., Guerra, G.P., Materazzi, S., Camilla, F.C., Nassini, R., Geppetti, P., Ferreira, J. 2013. Transient receptor potential ankyrin receptor stimulation by hydrogen peroxide is critical to trigger pain during monosodium urate-induced inflammation in rodents. Arthritis Rheum. 65: 2984-2995. 
Uversky, V.N. 2004. Neurotoxicant-induced animal models of Parkinson's disease: understanding the role of rotenone, maneb and paraquat in neurodegeneration. Cell Tissue Res. 318: 225-241.

Valko, M., Leibfritz, D., Moncol, J., Cronic, M.T.D., Mazur, M., Telser, J. 2007. Free radicals and antioxidants in normal physiological functions and human disease. Int $\mathbf{J}$ Biochem. Cell. Biol. 39: 44-84.

Vargas, S.J., Qi, C., Podolsky, E., Lee, D. 2014. A new Drosophila model to study the interaction between genetic and environmental factors in Parkinson's disease. Brain Res. 2: 1583:277-86.

Villegas, L.F., Marçalo, A., Martin, J., Fernández, I.D., Maldonado, H., Vaisberg, A.J., Hammond, G.B. 2011. (+) epi-Alpha-bisabolol [correction of bisbolol] is the woundhealing principle of Peperomia galioides: investigation of the in vivo wound-healing activity of related terpenoids. J. Nat. Product. 64(10): 1357-1359.

\section{FIGURE LEGENDS}

Fig. 1. Effect of (-)- $\alpha$-bisabolol on survival rate of flies exposed to rotenone. Data were collected every $24 \mathrm{~h}$ for each group. The number of flies (75 per group) was the sum of three independent experiments. Flies treated with rotenone and rotenone + BISA were followed until death of all subjects, whereas the control, and BISA alone were followed 
until 20 days of treatment. Statistical analysis was performed using the Log - rank (Mantel-Cox) Test. Survival curves are significant different, with $\mathrm{p}<0.001$.

Fig. 2. Effect of (-)- $\alpha$-bisabolol on geotaxic response (climbing of flies exposed to rotenone for 7 days. The total number of flies (30 per group) represents the sum of three independent experiments (10 flies/ assay). ***Significant difference in relation to the control group, $(\mathrm{p}<0.001)$; \# Significant difference between ROT and flies treated with rotenone plus BISA $5 \mu \mathrm{M}$ and BISA $25 \mu \mathrm{M} \quad(\mathrm{p}<0.05)$, \#\# Significant difference between ROT and ROT + BISA $250 \mu \mathrm{M}(\mathrm{p}<0.01)$.

Fig. 3. qPCR relative gene expression of catalase (CAT) (3a), superoxide dismutase (SOD) (3b), and keapl (3c). Results are expressed as mean \pm S.E.M $(n=3)$. The data are from 3 independent homogenizations of 20 flies each, and qPCR quantification was performed in duplicate. $*$ Significant difference in relation to control group $(\mathrm{p}<0.05)$, \#\# Significant difference in relation to ROT treatment $(\mathrm{p}<0.01)$.

Fig. 4. Effect of (-)- $\alpha$-bisabolol on total thiol content in homogenates of flies exposed to rotenone. $* *$ Significant difference in relation to control group $(\mathrm{p}<0.01)$.

Fig. 5. Effect of (-)- $\alpha$-bisabolol on mitochondrial complex I activity assayed in homogenates of flies exposed to rotenone. ***Significant difference in relation to control group $(\mathrm{p}<0.001)$.

Fig 6. Effect of BISA on Western blot analysis of TH in homogenates of flies exposed to rotenone 
TABLE 1 - Genes tested by quantitative real-time RT-PCR analysis and used forward and reverse primers

\begin{tabular}{c|c} 
Genes & Primer sequences \\
\hline Catalase & 5'ACCAGGGCATCAAGAATCTG 3' \\
& 5'AACTTCTTGGCCTGCTCGTA 3' \\
\hline Superoxide dismutase & 5'GGAGTCGGTGATGTTGACCT 3' \\
& 5'GTTCGGTGACAACACCAATG 3' \\
\hline KEAP 1 & 5' CCAACTTCCTCAAGGAGCAG 3' \\
& 5'CGGCGACAAATATCATCCTT 3' \\
\hline
\end{tabular}




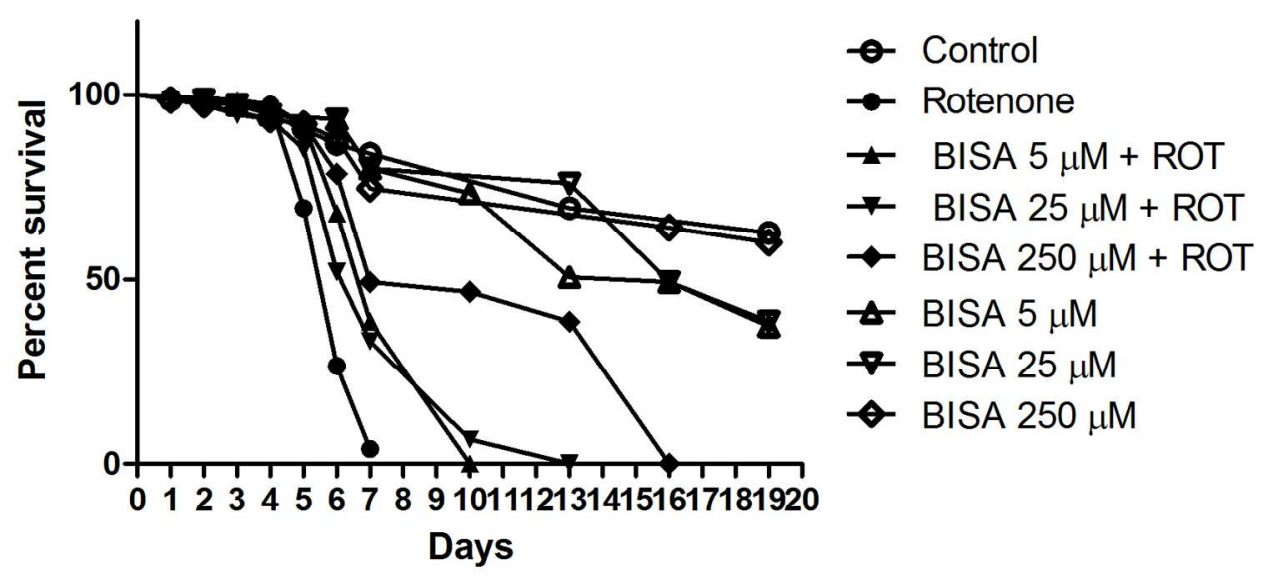

Effect of (-)-a -bisabolol on survival rate of flies exposed to rotenone. Data were collected every $24 \mathrm{~h}$ for each group. The number of flies ( 75 per group) was the sum of three independent experiments. Flies treated with rotenone and rotenone + BISA were followed until death of all subjects, whereas the control, and BISA alone were followed until 20 days of treatment. Statistical analysis was performed using the Log rank (Mantel -Cox) Test. Survival curves are significant different, with $p<0.001$.

$149 \times 78 \mathrm{~mm}(300 \times 300 \mathrm{DPI})$ 


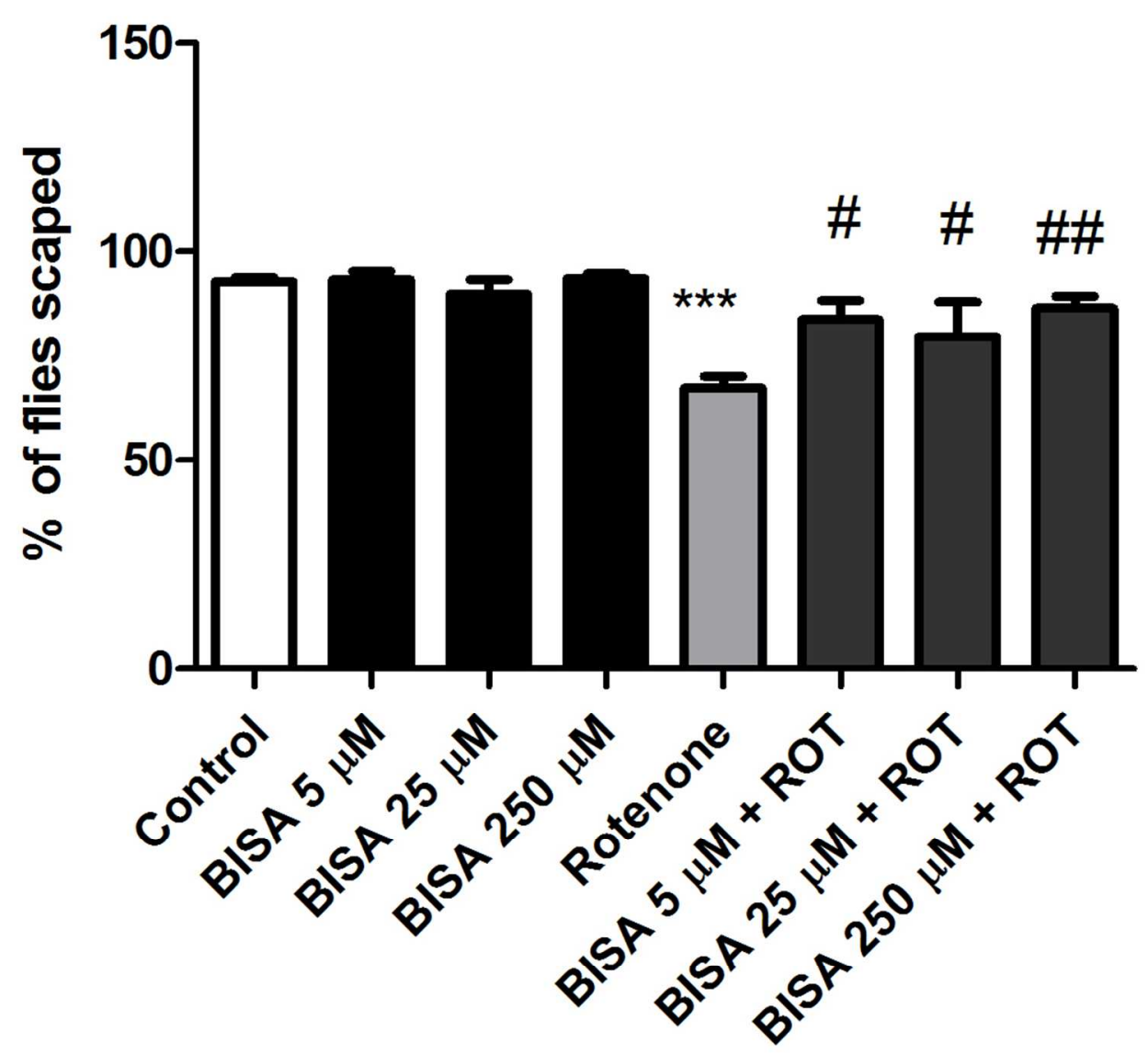

Effect of (-)-a-bisabolol on geotaxic response (climbing of flies exposed to rotenone for 7 days. The total number of flies (30 per group) represents the sum of three independent experiments (10 flies/ assay). $* * *$ Significant difference in relation to the control group, $(p<0.001)$; \# Significant difference between ROT and flies treated with rotenone plus BISA $5 \mu \mathrm{M}$ and BISA $25 \mu \mathrm{M}(\mathrm{p}<0.05)$, \#\# Significant difference between ROT and ROT + BISA $250 \mu \mathrm{M}(\mathrm{p}<0.01)$.

$97 \times 92 \mathrm{~mm}(300 \times 300$ DPI $)$ 
A
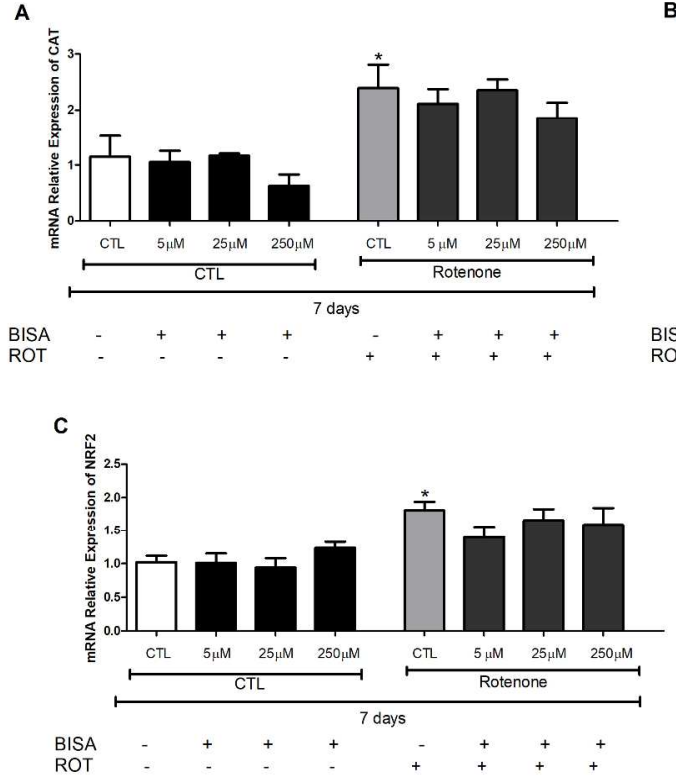

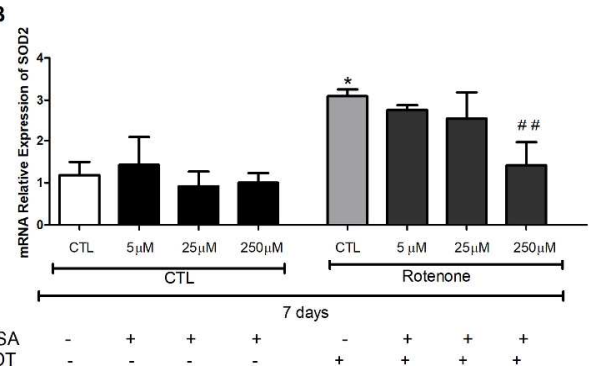

qPCR relative gene expression of catalase (CAT) (3a), superoxide dismutase (SOD) (3b), and keap1 (3c). Results are expressed as mean \pm S.E.M $(n=3)$. The data are from 3 independent homogenizations of 20 flies each, and qPCR quantification was performed in duplicate. *Significant difference in relation to control group $(p<0.05)$, \#\# Significant difference in relation to ROT treatment $(p<0.01)$.

$$
299 \times 188 \mathrm{~mm}(300 \times 300 \text { DPI })
$$




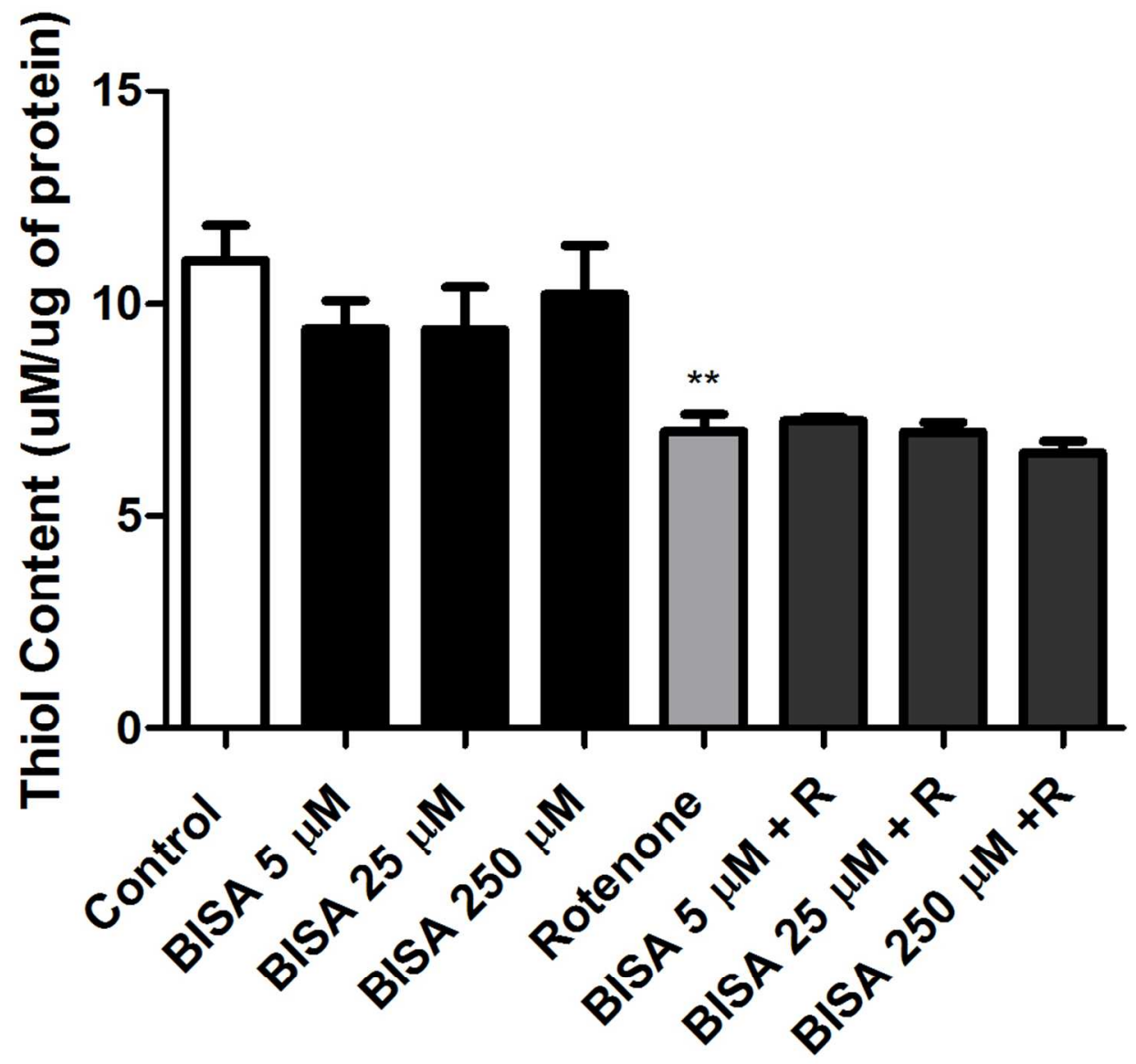

Effect of (-)-a -bisabolol on total thiol content in homogenates of flies exposed to rotenone.**Significant difference in relation to control group $(p<0.01)$.

$$
94 \times 90 \mathrm{~mm}(300 \times 300 \mathrm{DPI})
$$




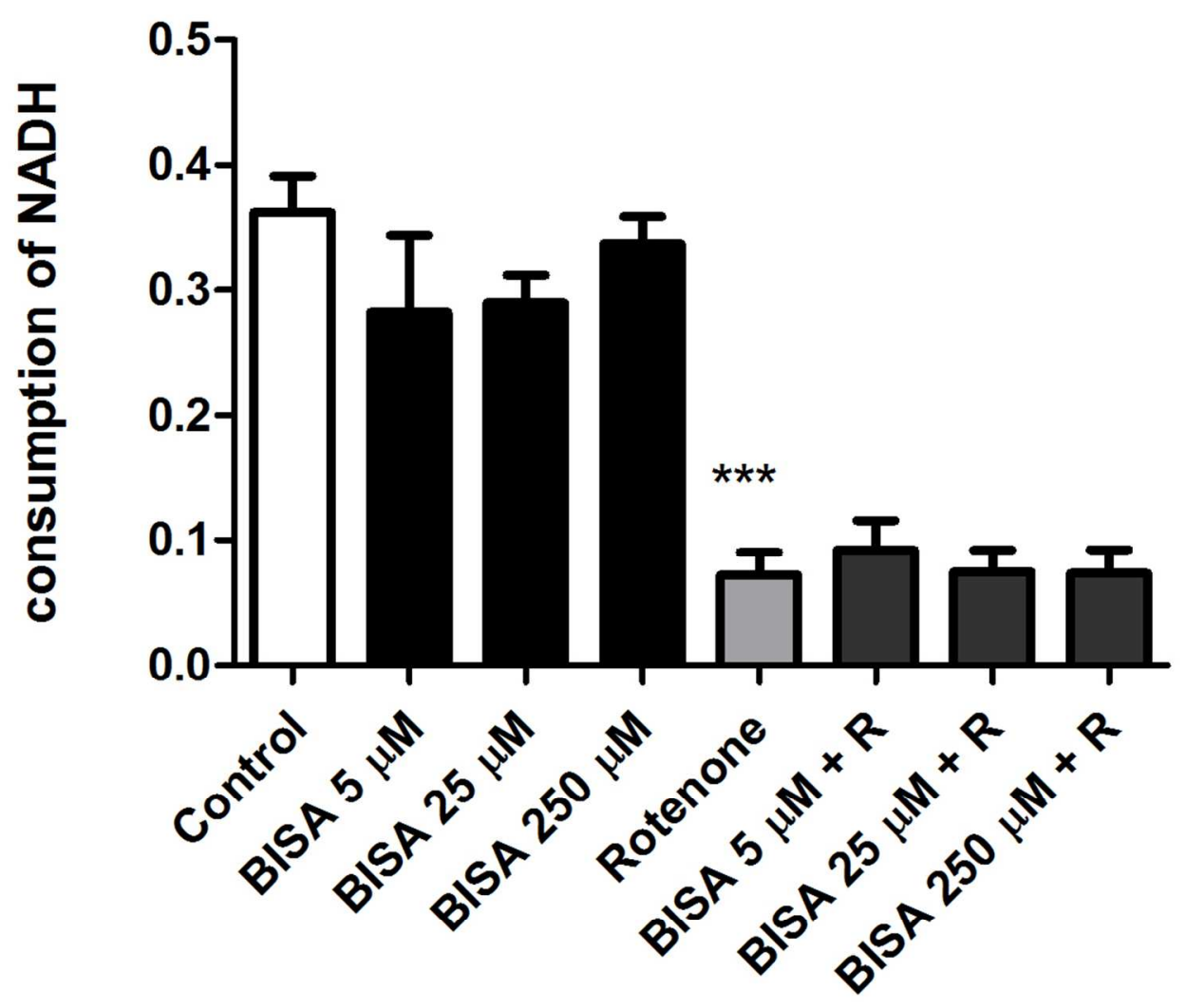

Effect of (-)-a -bisabolol on mitochondrial complex I activity assayed in homogenates of flies exposed to rotenone. ${ }^{* * *}$ Significant difference in relation to control group $(p<0.001)$.

$99 \times 88 \mathrm{~mm}(300 \times 300$ DPI $)$ 


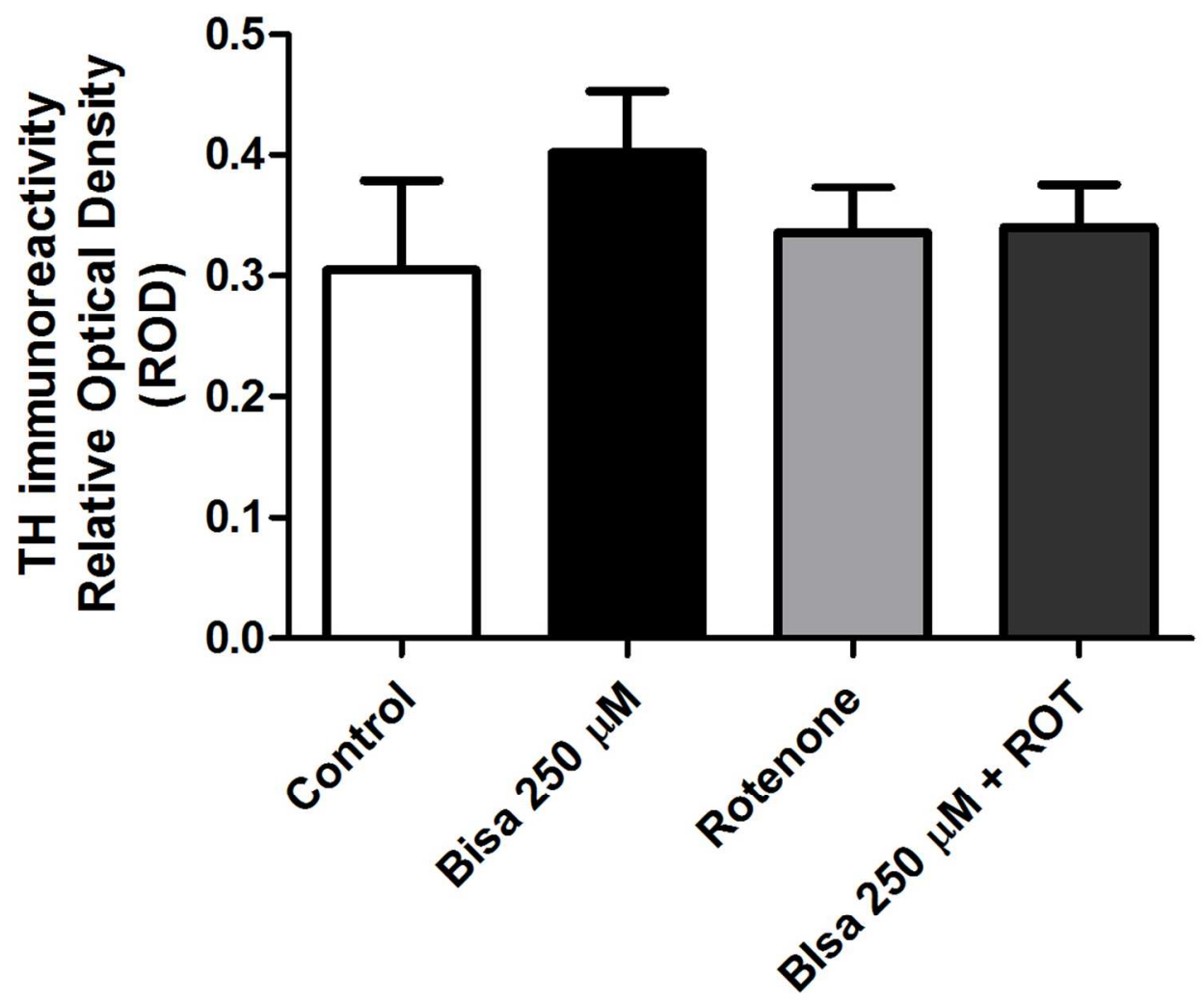

Effect of BISA on Western blot analysis of TH in homogenates of flies exposed to rotenone. $105 \times 91 \mathrm{~mm}(300 \times 300 \mathrm{DPI})$ 